\title{
Effect of Corrosion Inhibitor Used in Surface Treatment on the Anticorrosive Performance of an Epoxy Paint System
}

\author{
Jorge Felipe Ramos Pontes, Elber Vidigal Bendinelli, Cristina da Costa Amorim, Marcos Martins de Sá, \\ Alberto Pires Ordine
}

Cepel-Electric Energy Research Center, Corrosion Laboratory, Rio de Janeiro, Brazil

Email:ma2@cepel.br

How to cite this paper: Pontes, J.F.R., Bendinelli, E.V., da Costa Amorim, C., de Sá, M.M. and Ordine, A.P. (2016) Effect of Corrosion Inhibitor Used in Surface Treatment on the Anticorrosive Performance of an Epoxy Paint System. Materials Sciences and Applications, 7, 593-609.

http://dx.doi.org/10.4236/msa.2016.710049

Received: August 26, 2016

Accepted: October 9, 2016

Published: October 12, 2016

Copyright $\odot 2016$ by authors and Scientific Research Publishing Inc. This work is licensed under the Creative Commons Attribution International License (CC BY 4.0).

http://creativecommons.org/licenses/by/4.0/

\begin{abstract}
The mechanism of corrosion is mainly sustained by an electrochemical process, in which anodic and cathodic reactions take place, keeping their kinetics alive by electrons and ions fluxes. Several specific conditions can accelerate corrosion processes. When studying anticorrosive coatings, one of them is the contamination of metallic surface by soluble salts prior to coating, leading to premature failure of the paint system due to corrosion between the metallic surface and the coating. So the surface preparation step prior to coating is a procedure of great importance to the coating anticorrosive performance. The aim of this step is to clean the surface by removing visible and non-visible contaminants. Usually, wet abrasive blasting methods are the most efficient ones to achieve the latter objective, because they may clean the surface, create a surface roughness and also remove the non-visible contaminants, as they use water as a media. On the other hand, evaporation of water after blasting may create flash rust and to avoid this, it is common to use corrosion inhibitors in the water of wet blasting methods. In this paper, the use of sodium tetraborate (borax) as a corrosion inhibitor in wet abrasive blasting is discussed. Electrochemical measurements and mass loss tests show that a borax content of $1 \%$ in a saline solution has the best inhibitory action over carbon steel and zinc surfaces, allowing postponing for the painting step some time. However, residual borax left on the surface generated blistering and corrosion under coating, during accelerated corrosion test in a humidity condensation chamber. Electrochemical impedance spectroscopy confirmed that borax accelerated the permeation of water through the coating, downgrading the anticorrosive performance of the paint system.
\end{abstract}

\section{Keywords}

Wet Abrasive Blasting, Corrosion Inhibitor, Borax, Epoxy Paint System 


\section{Introduction}

The electrochemical mechanism of corrosion is the main one to explain most of the corrosion processes. So, the use of coatings as an impermeable barrier protecting the metal substrate from contact with the aggressive environment is a widespread and effective way to block the electrochemical reactions of corrosion [1]. It is also known that the performance of a paint system depends on the degree of surface cleaning prior to coating [2]. A good cleaning process able to remove visible and non-visible contaminants, generating an adequate roughness profile, prior to coating, is the key to success of the anticorrosive performance of any paint system [3].

Nowadays, the Brazilian Electric Energy Research Center, Cepel, is carrying out experimental research in the field of anticorrosive protection methods aiming to investigate alternative methods or new protection technologies against corrosion in order to reduce maintenance costs and increase productivity, while maintaining the same anticorrosive performance compared to traditional methods. Concerning surface preparation methods, wet abrasive blasting is already used in the maintenance of buried feet of the Brazilian transmission line towers [4] and is a promising option to be applied in the maintenance of galvanized steel structures from the above ground part of the transmission line towers. For instance, the great advantage of the method in comparison to manual surface treatment is its higher productivity and degree of cleaning. Besides removing visible contaminants, the wet abrasive blasting gives the benefit of removing non-visible contaminants, such as soluble salts, known to damage the anticorrosive performance of paint systems if left in the metallic surface prior to coating [3]. However, wet blasting methods may cause flash rust [5]-[7].

The term flash rust refers to an instantaneous surface oxidation of steel, appearing mainly after wet abrasive blasting or high pressure water jetting processes [5]-[7]. The phenomenon occurs while waterjet-cleaned steel dries off, quickly changing its surface appearance [8]. The color of flash rusted surface may vary depending on the time passed after jetting and composition of the steel [9], the time of wetness on the substrate prior to drying [5] and the quality of substrate cleaning [7]. If flash rust is present in the surface, the anticorrosive performance of the paint may be harmed and cause premature failure of the paint system.

Corrosion inhibitors are used to retard the formation of flash rust on metallic surface, allowing a longer time interval to new painting. On the other hand, if a corrosion inhibitor is a soluble salt, it could be a non-visible contaminant in the metallic surface prior to coating, and consequently premature failures of the paint system may be observed [10]. Sodium tetraborate (borax) is one example of a corrosion inhibitor which can be used for avoiding flash rust, it is soluble in water and regarded as an anodic inhibitor [11]-[13].

So, in this work, the influence of borax was investigated as a corrosion inhibitor in wet abrasive blasting processes during anticorrosive protection of metallic structures and electrical equipment. The performance of a painting system was evaluated in accelerated corrosion tests when residues of different contents of borax were left between 
the metallic substrate and the coating. This study gave important results for the technical requirements of Brazilian Standards used in the Electric Power Sector, concerning corrosion protection services [14].

\section{Materials and Methods}

In this work, two kinds of samples were prepared with complementary purposes. Unpainted metal samples of carbon steel SAE 1010 and zinc were used to evaluate the inhibitor behavior of borax solutions, by means of mass loss and electrochemical tests. The same metal samples, but painted with an epoxy coating, were prepared, simulating different contents of borax in a wet abrasive blasting, during the surface treatment step, in order to evaluate the anticorrosive behavior of the paint systems. For this investigation, an accelerated corrosion test in a humidity condensation chamber was applied.

For the mass loss test unpainted metal samples were dry blasted and sandpapered to a smooth finish. The samples were weighted prior to the test and immersed for 7 days in solutions of $3.5 \%$ sodium chloride $(\mathrm{NaCl})$, with different contents of borax (\% w/w): $0 \%, 0.25 \%, 0.5 \%, 1 \%, 2.5 \%$ and $5 \%$. After the test, samples were etched and weighted until constant weight to determine the corrosion rate of the metals in the different borax media, according to ISO 8407 Standard [15].

The electrochemical measurements were carried out in the same solutions mentioned above. For these tests, circular metal electrodes with $3.14 \mathrm{~cm}^{2}$ of area were sandpapered to a smooth finish and immersed in the solutions, in a conventional three-electrode electrochemical cell. Graphite was set as the counter electrode and saturated calomel as the reference electrode (SCE). In order to infer the inhibitor mechanism of the borax solutions, after one hour of the work electrode stabilization in the open circuit potential (OCP), anodic polarization curves were obtained up to $100 \mathrm{mV}$ of overvoltage from $\mathrm{OCP}$ at a scanning rate of $0.1 \mathrm{mV} / \mathrm{s}$, with the assistance of an Autolab Potentiostat.

The experimental tests with the painted metal samples were carried out also using carbon steel and zinc as the metallic substrates, which were treated by dry abrasive blasting and washed by brush with different solutions prior to coating. The degree of cleaning obtained after abrasive blasting was a near white standard, with an average roughness profile of $50 \mu \mathrm{m}$. After the dry abrasive blasting process and prior to coating, metal samples were treated, producing four different surface conditions that are indentified in Table 1.

Table 1. Identification of metal samples, according to the surface condition after dry abrasive blasting.

\begin{tabular}{cl}
\hline Sample identification & Surface condition prior to coating \\
\hline D & Dry surface, as obtained from the dry abrasive blasting process. \\
W & Wet surface, washed with deionized water, after the dry abrasive process. \\
1B & Wet surface, washed with a $1 \%$ borax solution, after the dry abrasive process. \\
5B & Wet surface, washed with a $5 \%$ borax solution, after the dry abrasive process. \\
\hline
\end{tabular}


After surface preparation, the samples were dried at ambient laboratory condition, temperature of $(23 \pm 1)^{\circ} \mathrm{C}$ and relative air humidity of $(60 \pm 1) \%$, and were painted with two-layer solvent-borne epoxy paint. A light degree of flash rust was developed on the surface of samples $\mathrm{W}$ and $1 \mathrm{~B}$. The degree of rusting found on the surface of samples $5 \mathrm{~B}$ was higher than the previous samples and classified as a moderate one. The average dry thickness of the coating in all surface conditions was the same and equal to $100 \mu \mathrm{m}$.

The corrosion accelerated test was carried out with the painted metal samples in a humidity condensation chamber for 744 hours, at $40^{\circ} \mathrm{C}$ and $100 \%$ of relative air humidity, according to ASTM D 4585 Standard [16]. During the test, the degree of blistering was evaluated following ISO 4628-2 [17]. The procedure reproduced a very aggressive condition of high relative air humidity and, indirectly, was useful to evaluate coating permeability. So, the effect of borax (left as a residue between metal substrate and coating) to permeability and anticorrosive performance of the paint system could be accessed by this test. Pull-off adhesion tests were performed before and after the corrosion accelerated test, according to ASTM D 4541 [18].

Additionally, an area of $12 \mathrm{~cm}^{2}$ of unpainted and painted metal samples was immersed in a solution of $3.5 \% \mathrm{NaCl}$, in order to perform electrochemical impedance spectroscopy (EIS), after OCP stabilization. These measurements were carried out in the OCP, with a potential amplitude perturbation of $10 \mathrm{mV}$ (unpainted metal samples) or $15 \mathrm{mV}$ (painted metal samples). Frequency scanning ranged from $40 \mathrm{kHz}$ to $4 \mathrm{mHz}$.

\section{Results and Discussion}

\subsection{Mass Loss Test}

By mass loss test, it was possible to calculate the corrosion rate of carbon steel and zinc with different borax concentrations in $\mathrm{NaCl} 3.5 \%$ solutions and verify in which conditions borax acts as a corrosion inhibitor for these metals. Figure 1 shows corrosion rate results of carbon steel and Figure 2, of zinc. Besides, the average error is also indicated in the figures, as each experiment was carried out with three replica samples.

Figure 1 shows that when adding a small amount of borax in the solution (0.25 to $0.5 \%$ ), the reduction of corrosion rate is not significant, if compared to $3.5 \% \mathrm{NaCl}$ solution ("blank"). When borax concentration was equal to $1 \%$, the reduction of the corrosion rate was considerable and of approximately $45 \%$ compared with $3.5 \% \mathrm{NaCl}$ solution without inhibitor. However, as more borax was added to the solution, the corrosion rate increased, which is not very common to happen. This may be related to the nature of borax, which is an oxidizing substance and an excess of it in the solution may accelerate the corrosion of steel.

In field services, the blasting process is an open operation and it is not possible to have an effective control of the inhibitor concentration on the steel surface. In fact, this type of control could only be achieved in closed systems with sensors for monitoring the instantaneous concentration of the inhibitor in the solution, and a control system to adjust inhibitor concentration when necessary. So, it would be difficult to maintain the corrosion inhibitor concentration at $1 \%$ in the mettalic surface, while performing wet 
abrasive blasting processes.

Figure 2 shows zinc corrosion rate in $\mathrm{NaCl}$ solutions with different concentrations of borax. It can be seen that there happened an effective reduction of corrosion rate in low concentrations, between $0.25 \%$ and $1 \%$, a fact that did not occur with carbon steel. The optimum inhibitory concentration was again $1 \%$, for zinc substrate, and after this value, the zinc corrosion rate kept at a constant level, independently of borax concentration. This fact means that borax addition, in concentration higher than $1 \%$, did not improve its corrosion inhibition performance. In fact, this excess would increase only the operating costs by using a larger amount of inhibitor.

Figure 3 shows the comparative performance of borax as an inhibitor of corrosion for carbon steel and zinc. It can be seen that there is a reduction of corrosion rate in

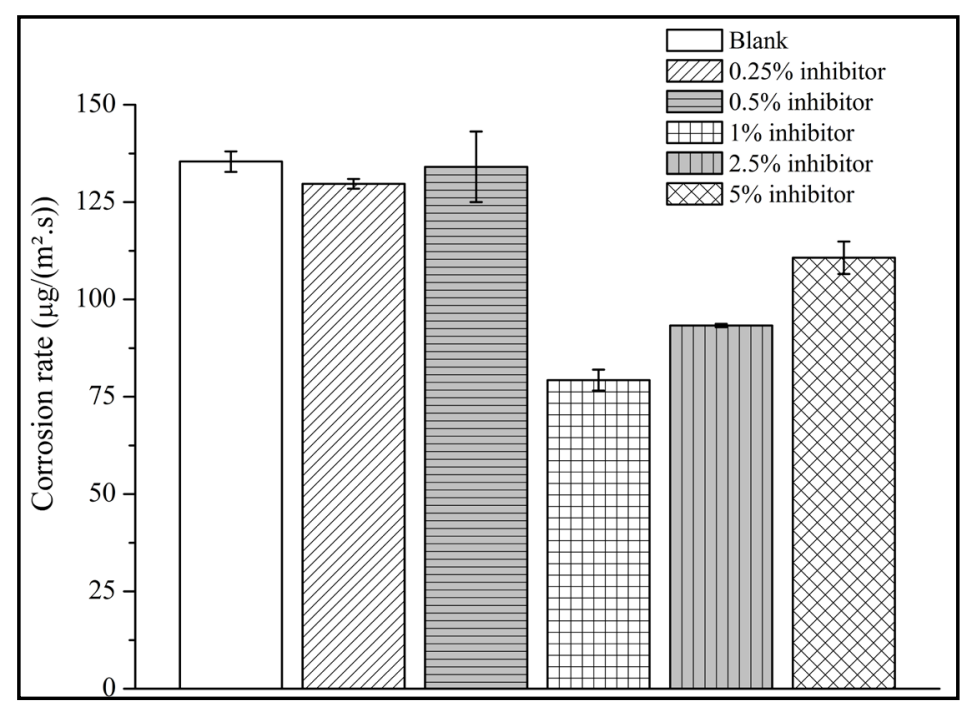

Figure 1. Carbon steel corrosion rate in $\mathrm{NaCl}$ solution with different concentrations of borax.

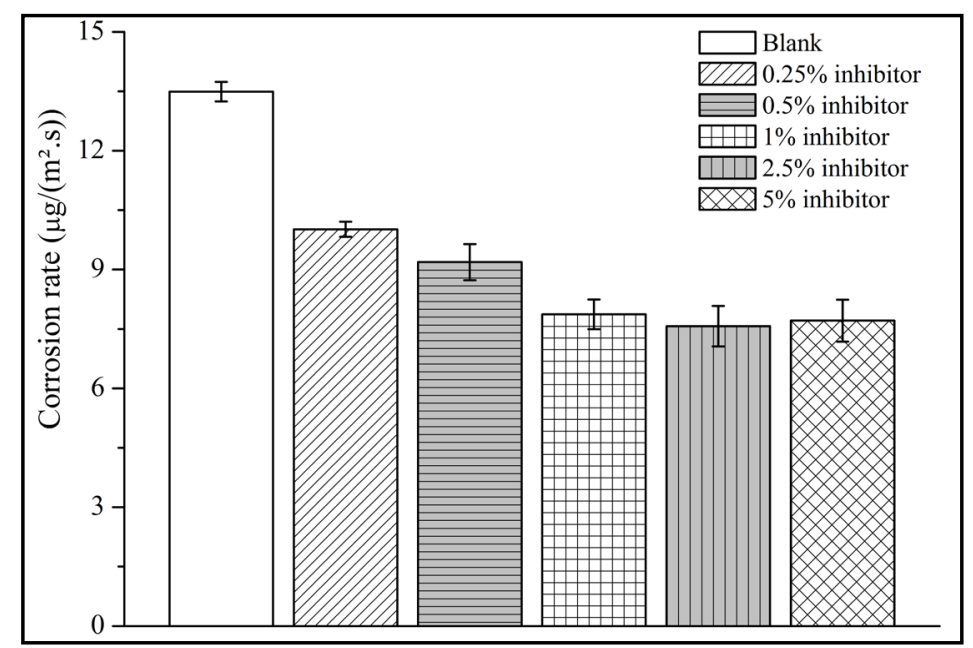

Figure 2. Zinc corrosion rate in $\mathrm{NaCl}$ solution with different concentrations of borax. 


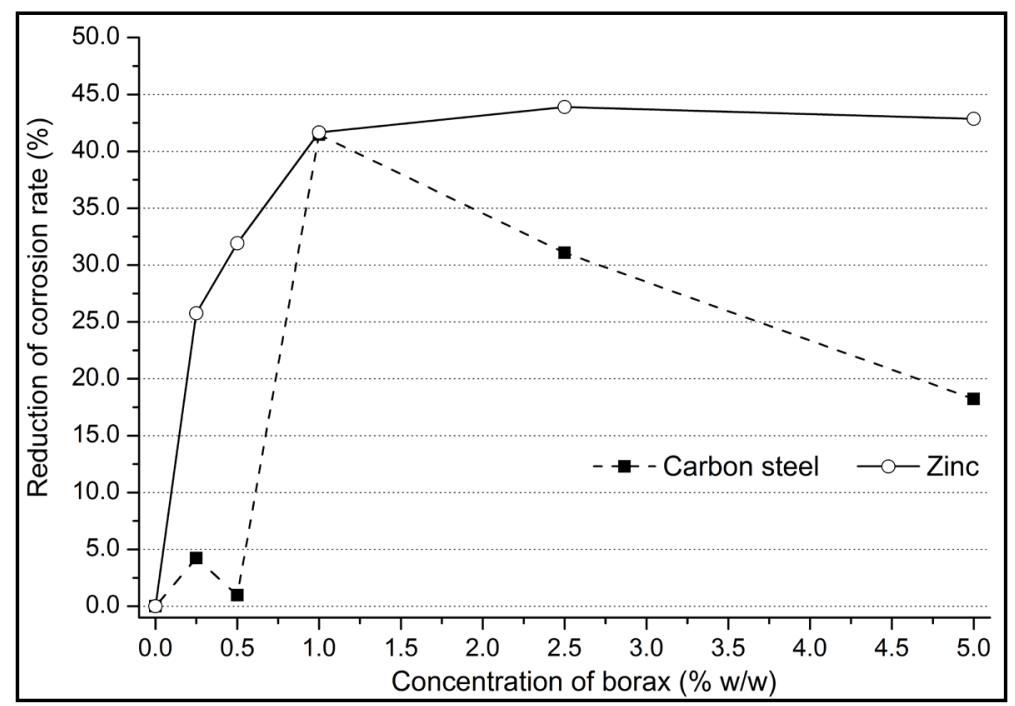

Figure 3. Reduction of corrosion rate for carbon steel and zinc in different concentrations of borax.

both cases, but with different mechanisms of action. It is remarkable that in both substrates, borax had optimum inhibitory concentration efficiency at about $1 \%$. However, in the case of carbon steel, increasing the concentration more than $1 \%$ resulted in increasing the corrosion rate, what was not observed for zinc.

\subsection{Anodic Polarization}

In Table 2, there are values of OCP, current density at $10 \mathrm{mV}$ of anodic overvoltage and the inhibition efficiency at $3.5 \% \mathrm{NaCl}$ solutions, containing different concentrations of borax. The last parameter was calculated using Equation (1):

$$
E(\%)=\frac{i_{\mathrm{NaCl} 3.5 \%}-i_{\mathrm{borax}}}{i_{\mathrm{NaCl} 3.5 \%}} \times 100
$$

where: $E$ is the inhibition efficiency, $i$ is the current density at $10 \mathrm{mV}$ of anodic overvoltage, $\mathrm{NaCl} 3.5 \%$ is the index that stands for the $\mathrm{NaCl}$ solution and borax is the index that refers to the borax solution.

Table 2 shows that increasing the concentration of inhibitor is related to an increase of OCP, reducing the current density. These facts indicate that borax behaves as an anodic inhibitor, which is in agreement with the literature [13]. The concentration of $1 \%$ borax generated a greater reduction in current density, resulting in more efficient inhibition. This concentration of borax was also shown to be the optimum one in mass loss tests.

Anodic inhibitors act by blocking the anodic reaction, usually in contact with the corrosion products formed initially and generating an adherent and insoluble protective film on metal surface [13]. Through electrochemical measurements, this mechanism is evidenced by the increase of open circuit potential and decrease of current density in anodic polarization, precisely what was observed in the results of Table 2.

In Figure 4, it is possible to observe the anodic polarization curves for carbon steel in 
$3.5 \% \mathrm{NaCl}$ solutions, containing different concentrations of borax. It is clear that the addition of the inhibitor shifted anodic curves towards lower current density ranges as compared with the curve in $3.5 \% \mathrm{NaCl}$ solution without inhibitor. This kind of shift can be attributed to a decrease in the velocity of anodic reactions [1]. Still in Figure 4, higher current density reductions were observed with the concentrations of $1 \%$ and $2.5 \%$ borax, suggesting that the best inhibition effect is in this concentration range, a result that is also in agreement with mass loss tests. In fact, increasing borax concentration to $5 \%$, there was a decrease in the inhibitory effect, with a shift of the curve towards higher current densities.

In Figure 5 the influence of borax in the anodic curves of zinc is presented. By this result, the effect of different borax concentration is not as well defined as for carbon

Table 2. Open circuit potential (OCP), current density at $10 \mathrm{mV}$ of anodic overvoltage and inhibition efficiency for carbon steel and zinc. Reference electrode: saturated calomel.

\begin{tabular}{ccccc}
\hline Substrate & $\begin{array}{c}\text { Borax concentration } \\
\text { in } 3.5 \% \mathrm{NaCl}(\mathrm{v} / \mathrm{v})\end{array}$ & OCP $(\mathrm{V})$ & $\begin{array}{c}\text { Current density } \\
\left(\mu \mathrm{A} / \mathrm{cm}^{2}\right)\end{array}$ & $\begin{array}{c}\text { Inhibition } \\
\text { efficiency }(\%)\end{array}$ \\
\hline 0 & -0.69 & 6.56 & 30.5 \\
Carbon Steel & 0.25 & -0.55 & 4.56 & 25.5 \\
& 0.5 & -0.51 & 4.89 & 52.6 \\
& 1 & -0.49 & 3.11 & 47.1 \\
& 2.5 & -0.43 & 3.47 & 30.5 \\
Zinc & 0 & -0.44 & 4.56 & \\
& 1 & -1.09 & 716 & 79.2 \\
& 2.5 & -1.01 & 149 & 82 \\
& 5 & -0.92 & 129 & 84.6
\end{tabular}

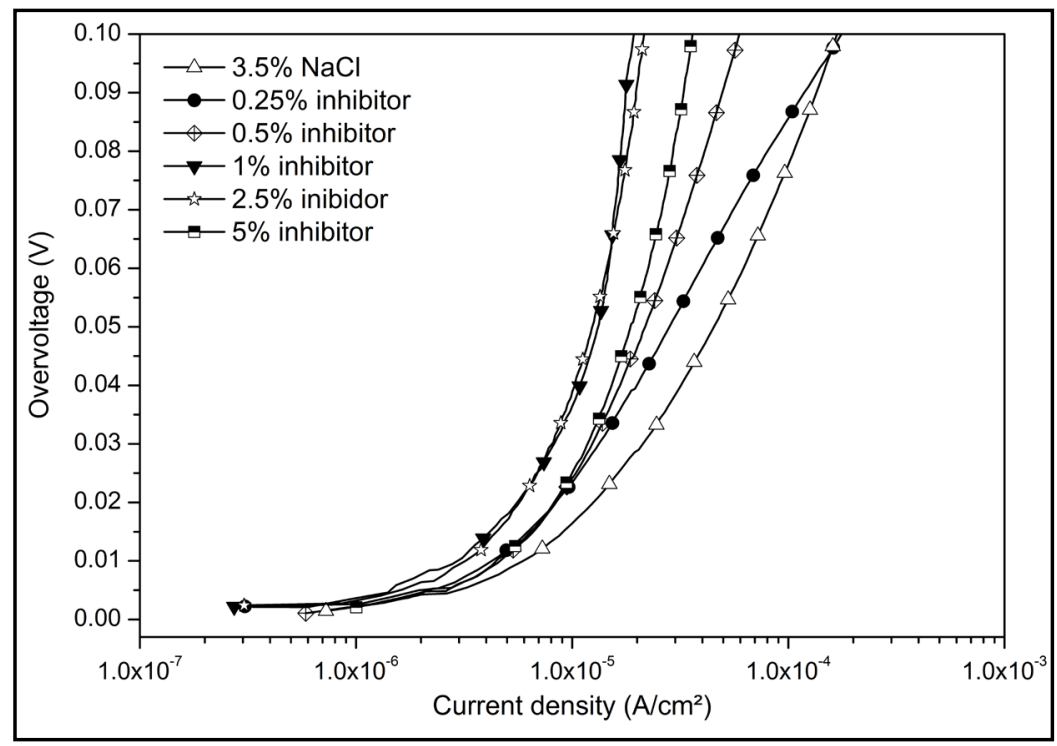

Figure 4. Anodic curves for carbon steel in $3.5 \% \mathrm{NaCl}$ solutions with different concentrations of borax. Reference electrode: saturated calomel. 


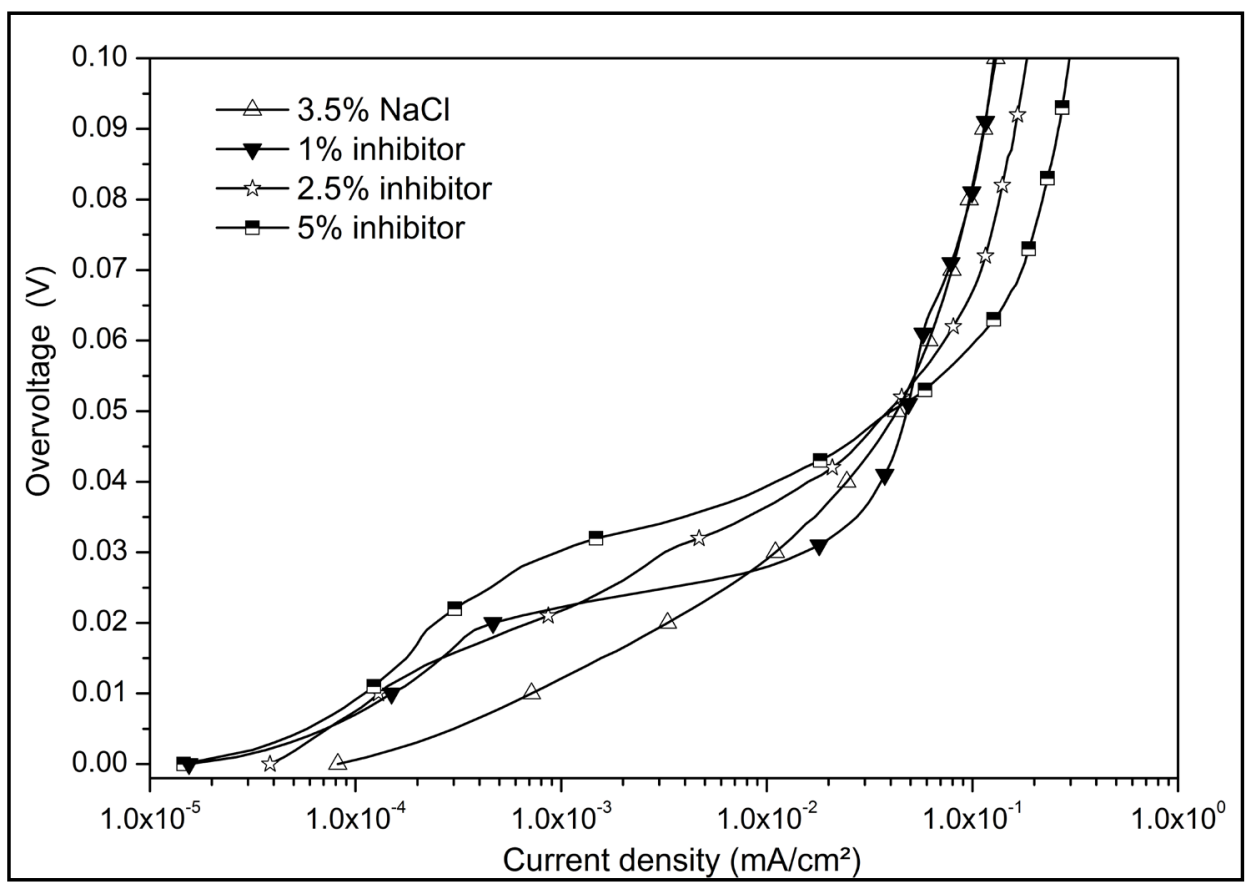

Figure 5. Anodic curves for zinc in $3.5 \% \mathrm{NaCl}$ solution with different concentrations of borax. Reference electrode: saturated calomel.

steel. However, there is a tendency at values of overvoltage lower than $0.04 \mathrm{~V}$, in which polarization curves confirmed the anodic inhibition behavior of borax and showed an efficient performance in reducing current densities as function of its concentrations in solutions.

Results presented so far allowed to evaluate inhibition characteristics of borax on unpainted metal samples. Besides that, it was also investigated the inhibitor effect to the performance of painted metal samples. The results are presented in the following items.

\subsection{Humidity Condensation Test}

In Figure 6, it can be observed the appearance of the carbon steel and zinc samples prepared with 5\% borax, after 24 hours of exposure in the humidity condensation test chamber, where both cases presented blistering. For carbon steel, blisters were classified as 4 (S3), while zinc presented blisters classified as 2 (S2), a smaller size and frequency when compared to carbon steel.

In Figure 7, it is observed the behavior of painted carbon steel samples under different conditions of preparation, tested in the humidity condensation chamber. After 360 hours of test, those samples prepared with $1 \%$ and $5 \%$ borax and painted showed blistering in the coating classified as 4 (S2) and 2 (S4), respectively. The other two conditions, one with flash rust without inhibitor and other treated with dry abrasive blasting, showed no defect in the coating, with similar anticorrosive performances in this test.

The results presented so far from the humidity condensation test were interesting to evaluate the permeability property of the paint system and its resistance to blistering in 


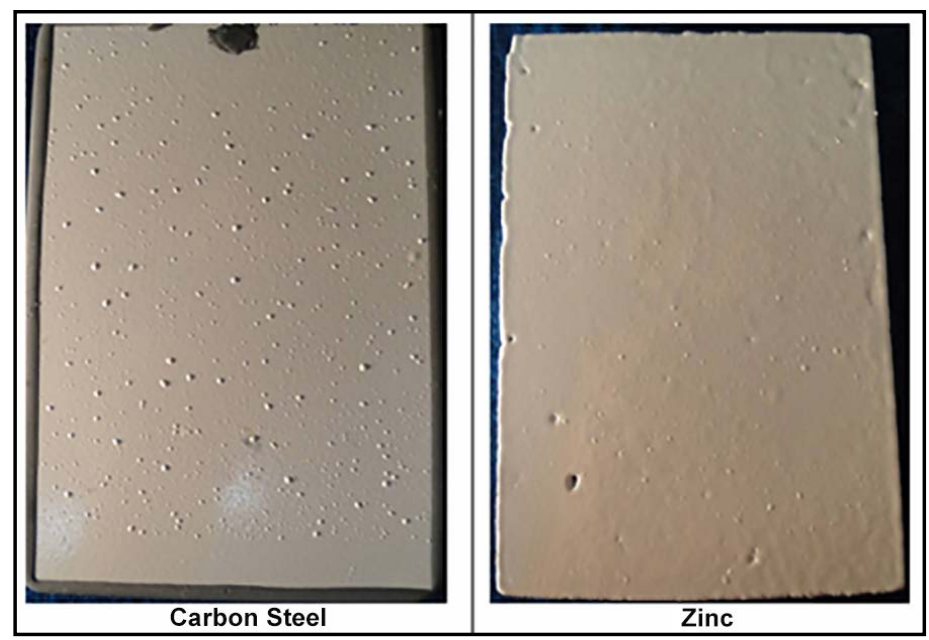

Figure 6. Visual aspect of samples prepared with $5 \%$ borax solution and painted, tested on humidity condensation chamber, after $24 \mathrm{~h}$ of test.

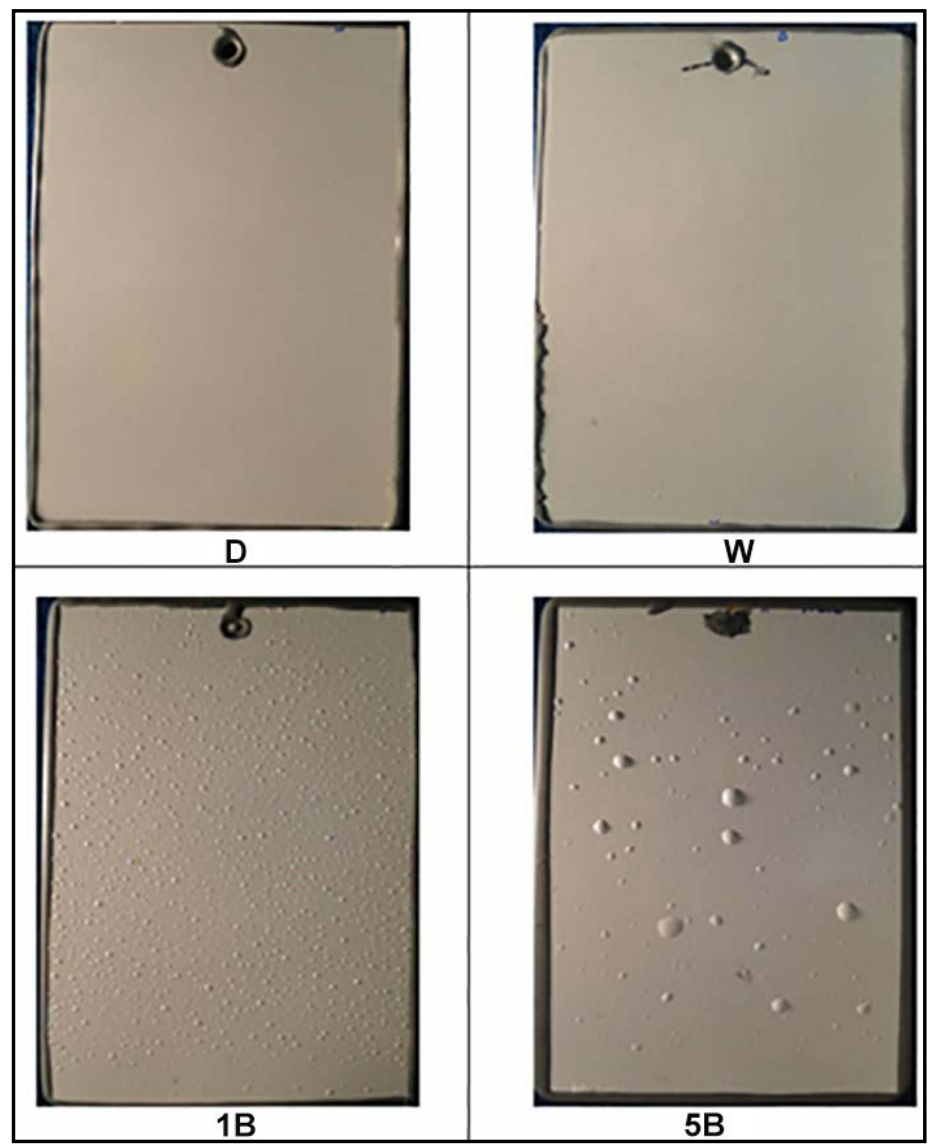

Figure 7. Painted carbon steel samples tested on the humidity condensation chamber after $360 \mathrm{~h}$. In the subtitles, D refers to the dry blasted painted sample, the other designations to the washed samples, using deonized water (W), 1\% borax solution (1B) and $5 \%$ borax solution (5B). 
a high humidity condition. Blistering formation is observed in this test especially if soluble salts are left between the substrate and the coating, because they are not properly removed during surface preparation step [3]. The mechanism that explains this experimental behavior was already studied [2]. Blistering occurs due to water permeation through coating, enhanced by osmotic pressure, once there is a difference in concentration of salt between the external and internal environment (metallic surface). As borax is a saline compound and hygroscopic, this mechanism may happen if borax is left in metallic surface prior to coating. The higher the salt concentration between the substrate and the coating, the more accelerated will be water permeation through coating. Then water hydrates the salt, which increases in volume, produces corrosion products and blisters in the coating, greatly reducing corrosion protection.

In Figure 8, it is observed the behavior of painted zinc samples under different conditions of preparation, tested in the humidity condensation chamber. After 336 hours of test, it can be seen that with painted zinc the osmotic effect was more pronounced than with painted carbon steel, as a considerable more intense damage resulted on the protective coating in the former. It is observed that all painted zinc samples showed blistering. The conditions with $1 \%$ and $5 \%$ with borax showed blisters classifications 2 (S5) and 3 (S5), respectively. The condition simulating flash rust without borax and the one obtained with dry abrasive blasting had blisters of 3 (S2) and 2 (S4) classifications, respectively. The difference between them was mainly the size of the blisters, which were larger in the first case.

Blistering was observed in all cases of painted zinc and this result cannot be uniquely related to the use of inhibitor in surface preparation. It should be considered that the paint system used is not suitable to be applied directly onto the zinc substrate, due to the generalized lower performance on this substrate in comparison to that applied on carbon steel.

It is known that painting galvanized steel or zinc requires the application of an adhesion primer, in order to assure a good anticorrosive performance of the paint system. Therefore, the effect of the inhibitor on the coating performance in zinc substrate was not clear, because of an inappropriate coating type for this base metal. It is worth mentioning, however, that for painted carbon steel samples, the use of the inhibitor was responsible for the lower performance of the paint compared to those conditions in which borax was absent.

After $744 \mathrm{~h}$ of test in the humidity condensation chamber, Figure 9 points out the visual aspects of the painted carbon steel samples, prepared without inhibitor in the surface. It can be observed the effect of flash rust compared to a dry blasted surface for the performance of the coating. The instantaneous oxide layer formed was not detrimental to the anticorrosive coating performance, because both samples presented similar behavior after the test.

The set of test results in the humidity condensation chamber, especially regarding the painting in carbon steel, shows that if the paint system is compatible with the presence of flash rust formed on the surface, when borax is absent, it is better not to use a hygroscopic corrosion inhibitor to prevent the formation of instantaneous oxidation. 


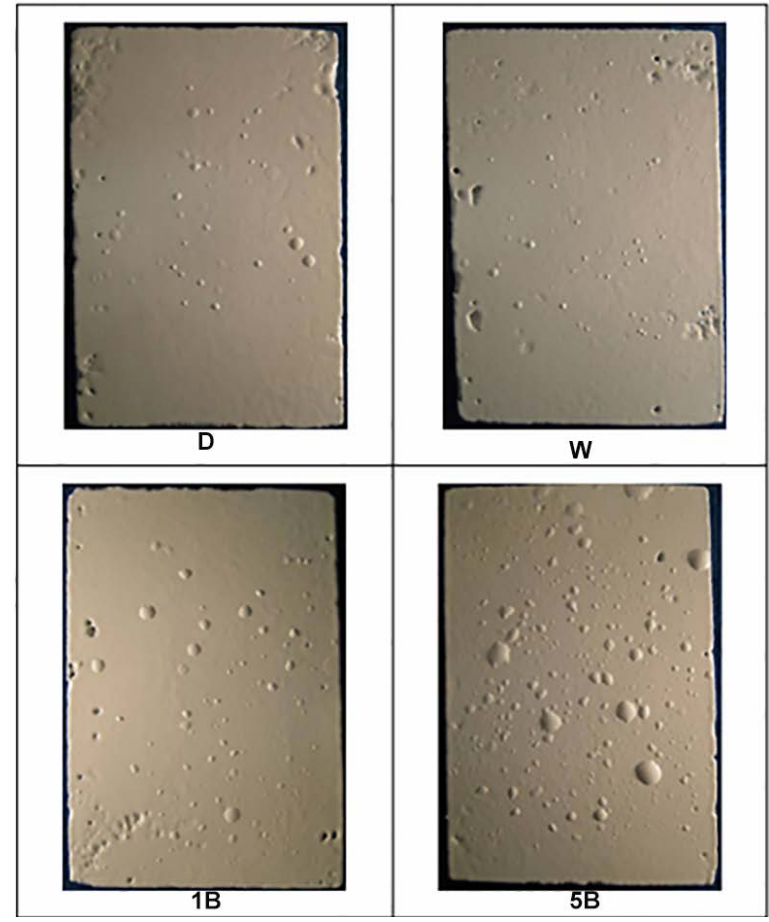

Figure 8. Painted zinc samples tested on the humidity condensation chamber after $336 \mathrm{~h}$. In the subtitles, D refers to the dry blasted painted sample, the other designations to the washed samples, using deonized water (W), 1\% borax solution (1B) and $5 \%$ borax solution (5B).
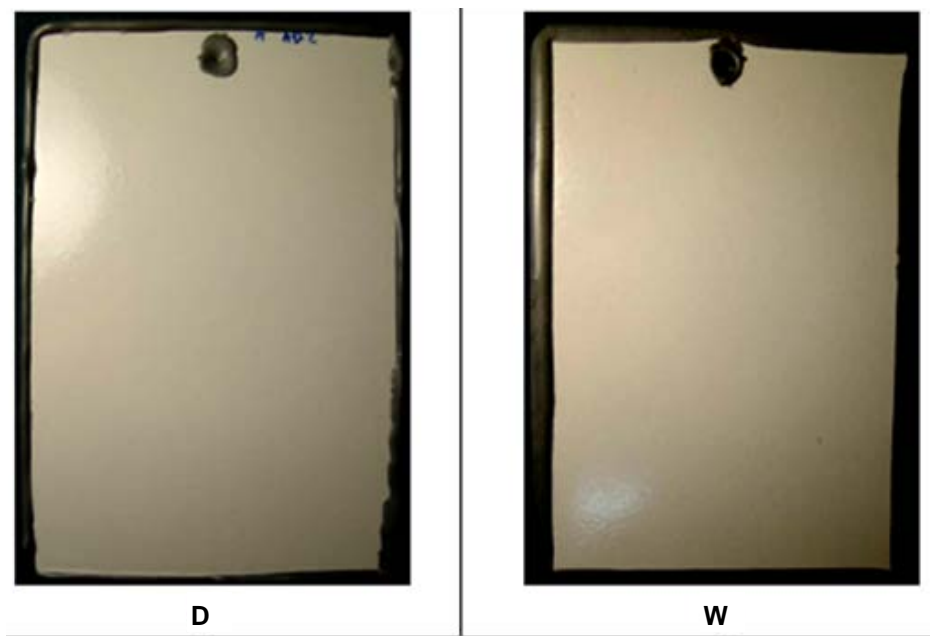

Figure 9. Painted carbon steel samples tested on the humidity condensation chamber after $744 \mathrm{~h}$. In the subtitles, D refers to the dry blasted painted sample, $\mathrm{W}$ to the washed one, using deonized water.

\subsection{Pull-Off Adhesion Tests}

Table 3 shows the results of adhesion, before and after the humidity condensation test for the different samples of painted carbon steel. It is possible to observe that the ten- 
Table 3. Adhesion results before and after the humidity condensation test.

\begin{tabular}{ccccc}
\hline \multirow{2}{*}{ Sample } & \multicolumn{2}{c}{ Before humidity test } & \multicolumn{2}{c}{ After humidity test } \\
\cline { 2 - 5 } & Tension (MPa) & Fail type & Tension (MPa) & Fail type \\
\hline D & 27.0 & B & 26.0 & $80 \%$ A/B, 20\% B \\
W & 17.1 & A/B & 25.0 & $80 \%$ A/B, 20\% B \\
1B & 8.7 & A/B & 9.0 & A/B \\
5B & 5.6 & A/B & 4.3 & A/B \\
\hline
\end{tabular}

sion values for sample D are higher than for all other samples. Sample $\mathrm{W}$ had a thin oxide layer without the presence of inhibitor, which was responsible for an adhesive loss between substrate and paint. However, tension values were kept high, differently from samples $1 \mathrm{~B}$ and $5 \mathrm{~B}$. In these cases, the presence of the inhibitor was responsible for a significant reduction on tension values, compared to samples $\mathrm{D}$ and $\mathrm{W}$.

\subsection{Electrochemical Impedance Spectroscopy}

Additional electrochemical tests were carried out with carbon steel samples. Table 4 presents polarization resistance data in $3.5 \% \mathrm{NaCl}$ solution, before coating the substrate. These values were obtained from the electrochemical impedance diagrams, in the limit of low frequency, after one hour of immersion.

Samples D and $\mathrm{W}$ showed the same value of resistance, while the addition of borax (samples $1 \mathrm{~B}$ and $5 \mathrm{~B}$ ) determined a significantly increase in the polarization resistance, showing the inhibitor effect of borax. This observation is coherent with the characterization of borax as an anodic inhibitor, already indicated by the polarization curves. Treatment with $1 \%$ borax solution showed a better anticorrosive performance, as in the previous tests with unpainted metal samples.

For the painted carbon steel samples, electrochemical impedance diagrams were obtained, after 24 hours of immersion in $3.5 \% \mathrm{NaCl}$ solution. Figure 10 shows the impedance diagrams for sample $\mathrm{D}$ in two different conditions, before and after the test on the humidity condensation chamber. Initially, the impedance at low frequency was close to $6 \mathrm{G} \Omega \cdot \mathrm{cm}^{2}$, which represents the coating resistance [1] and as the coating might have experienced some degradation during the test, the resistance decreased to 3 $\mathrm{G} \Omega \cdot \mathrm{cm}^{2}$. The frequencies at the maximum of both diagrams are in the same range, and the capacitances of the coating, calculated using these frequencies and the coating resistance [1] resulted in $0.5 \mathrm{nF} / \mathrm{cm}^{2}$ and $0.4 \mathrm{nF} / \mathrm{cm}^{2}$ for the painted samples before and after the corrosion test, respectively. So the coating resistances are in the same order of magnitude and the coating capacitances kept almost unchanged, suggesting that the barrier property of the paint system against the corrosive environment was maintained after the corrosion test and the diffusion of water to the substrate was slow.

Figure 11 shows the results of impedance measurements for sample $\mathrm{W}$, before and after the test on the humidity condensation chamber. Before and after the corrosion 
Table 4. Polarization resistance of carbon steel in $3.5 \% \mathrm{NaCl}$ solution, after one hour of immersion.

\begin{tabular}{cc}
\hline Sample & Polarization resistance $\left(\Omega \cdot \mathrm{cm}^{2}\right)$ \\
\hline D & 3480 \\
W & 3480 \\
1B & 5562 \\
5B & 4355 \\
\hline
\end{tabular}

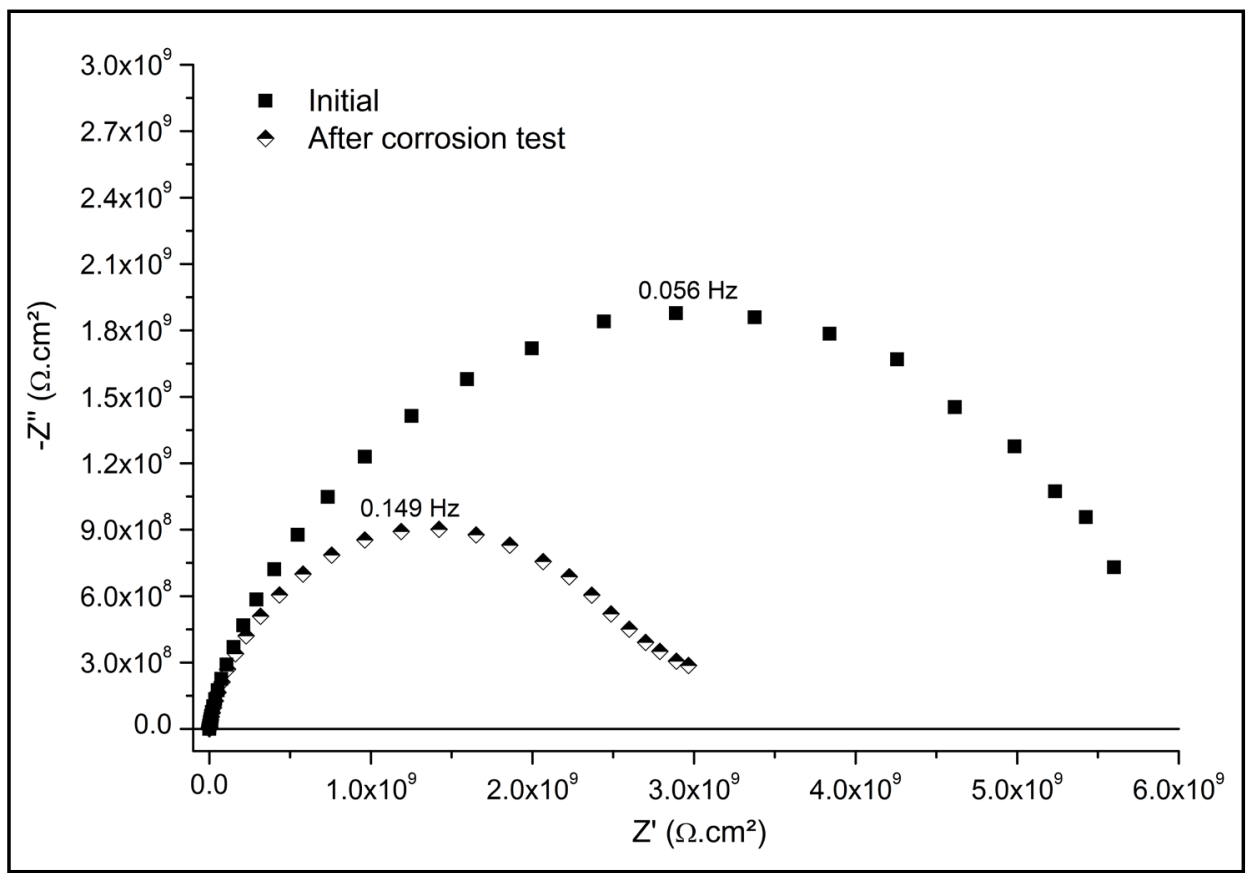

Figure 10. Nyquist plots for the dry blasted painted sample D of carbon steel, in $3.5 \% \mathrm{NaCl}$ solution.

test, the frequencies at the maximum of the semicircle of the diagrams are in the same range. It is possible to extrapolate the semicircles to find Z' and estimate the coating resistance. Before the corrosion test, the coating resistance was equal to $9 \times 10^{7} \mathrm{~cm}^{2}$ and after the test, to $8 \times 10^{7} \mathrm{~cm}^{2}$. So, after the test, the coating resistance showed a slight decrease and an additional resistive element tending to form a straight line superimposed at $45^{\circ}$ to both axes, in the range of low frequencies. This behavior resembles Warburg impedance, due to partial diffusion control [1]. In the case studied, it can be associated with the diffusion of water through the coating. Considering the coating capacitance, it was equal to $0.2 \mathrm{nF} / \mathrm{cm}^{2}$ for both diagrams, a value in the same range found for sample $\mathrm{D}$, suggesting that the barrier property is still good.

Figure 12 shows the results of impedance measurements for sample $1 \mathrm{~B}$, before and after the test on the humidity condensation chamber. This figure demonstrates the high impedance mismatch of the sample under the two conditions. Before the corrosion test, the paint system had a remarkable protective barrier property, showing a 


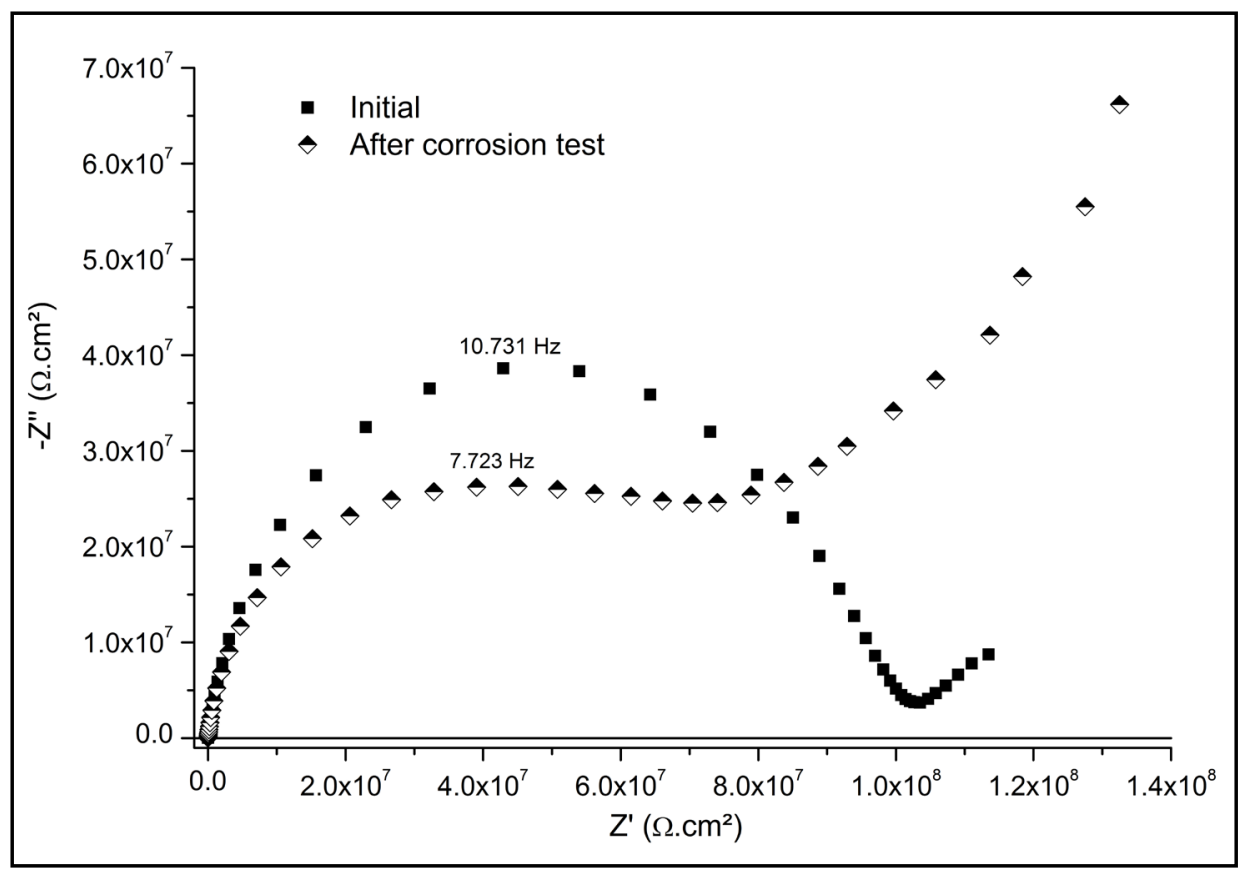

Figure 11. Nyquist plots for sample $\mathrm{W}$ of painted carbon steel, in $3.5 \% \mathrm{NaCl}$ solution.

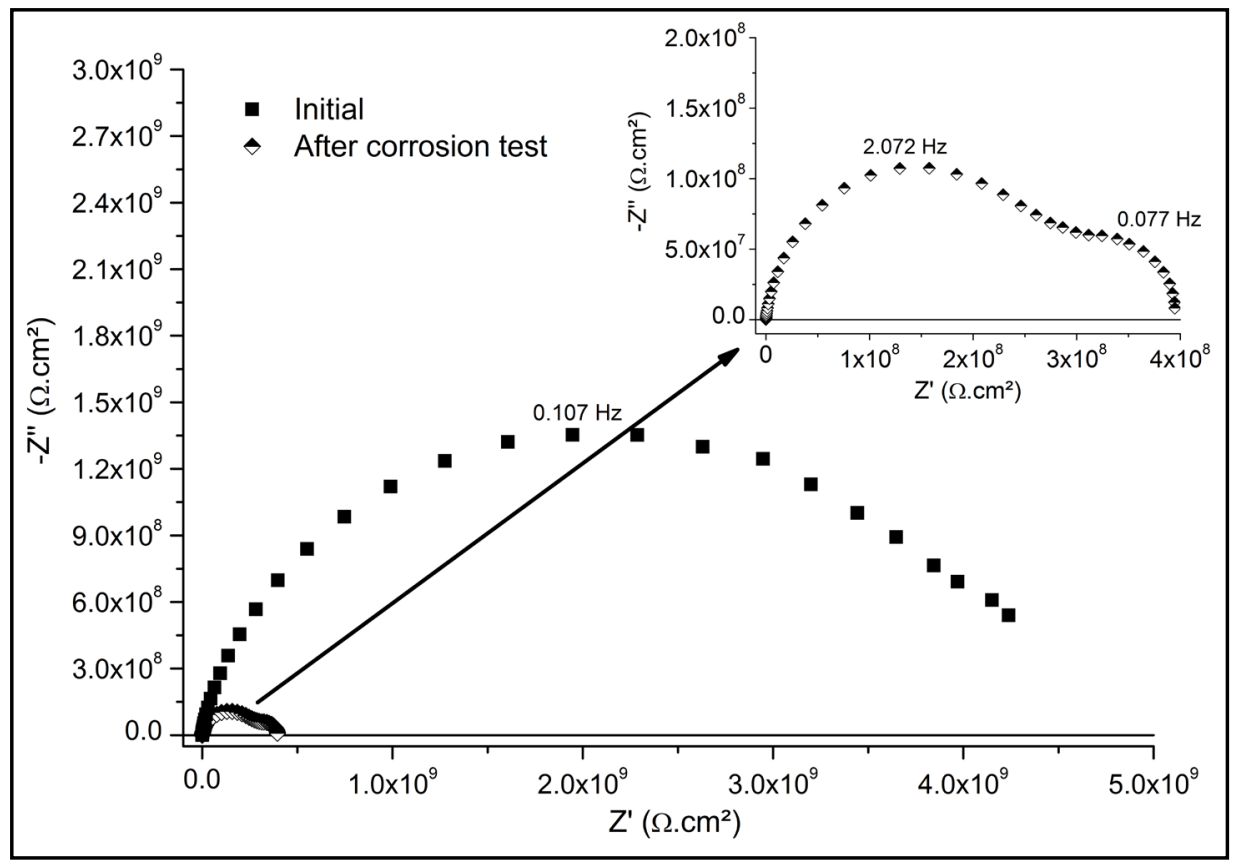

Figure 12. Nyquist plots for sample 1B of painted carbon steel, in $3.5 \% \mathrm{NaCl}$ solution.

coating resistance equal to $4 \mathrm{G} \Omega \cdot \mathrm{cm}^{2}$. After the test, there was a reduction of one order of magnitude in the coating resistance, which was equal to $0.3 \mathrm{G} \Omega \cdot \mathrm{cm}^{2}$. In this case, besides the reduction of the first capacitive loop impedance diagram, a second capacitive loop is shown in the range of low frequencies, which can be attributed to faradaic processes [1]. In fact, blistering was observed after the test and this impedance diagrams 
confirm that the barrier property of the coating was significantly reduced due to water permeability, accelerated by the presence of the inhibitor on the surface of the substrate.

Figure 13 shows the results of impedance measurements for sample 5B, before and after the test on the humidity condensation chamber. The coating resistance was equal to $16 \mathrm{G} \Omega \cdot \mathrm{cm}^{2}$ and to $0.001 \mathrm{G} \Omega \cdot \mathrm{cm}^{2}$, before and after the corrosion test, respectively. So, it was observed a decrease of four orders of magnitude in the coating resistance, after the test, compared to the initial condition. The test was very aggressive for this sample, resulting in a significant decrease in the impedance of the coating. This effect was also observed visually, with the formation of a high degree of blistering in the coating. In the figure expansion, there is the presence of two semicircles, the first one related to anticorrosive coating properties and the second one, to faradaic processes, which suggest a severe corrosion process under the coating.

In Figure 14, it is possible to analyze the Nyquist plots for painted carbon steel samples, in $3.5 \% \mathrm{NaCl}$ solution, before the humidity condensation test. The use of borax at the concentration of $5 \%$ resulted in the highest coating resistance of the paint system. Considering just this result, it could be prematurely concluded that this condition would be the ideal one, in terms of the anticorrosive performance.

However, after exposition of the coated samples to the accelerated corrosion test, the inhibitory effect of borax is vanished and as it is a hygroscopic salt, it acts accelerating the permeation of water through the coating, downgrading the anticorrosive performance of the paint system. By this mechanism, borax becomes rather a salt contaminant between metal and coating than a corrosion inhibitor, accelerating blistering and metal corrosion, when the paint system comes into use in aggressive conditions.

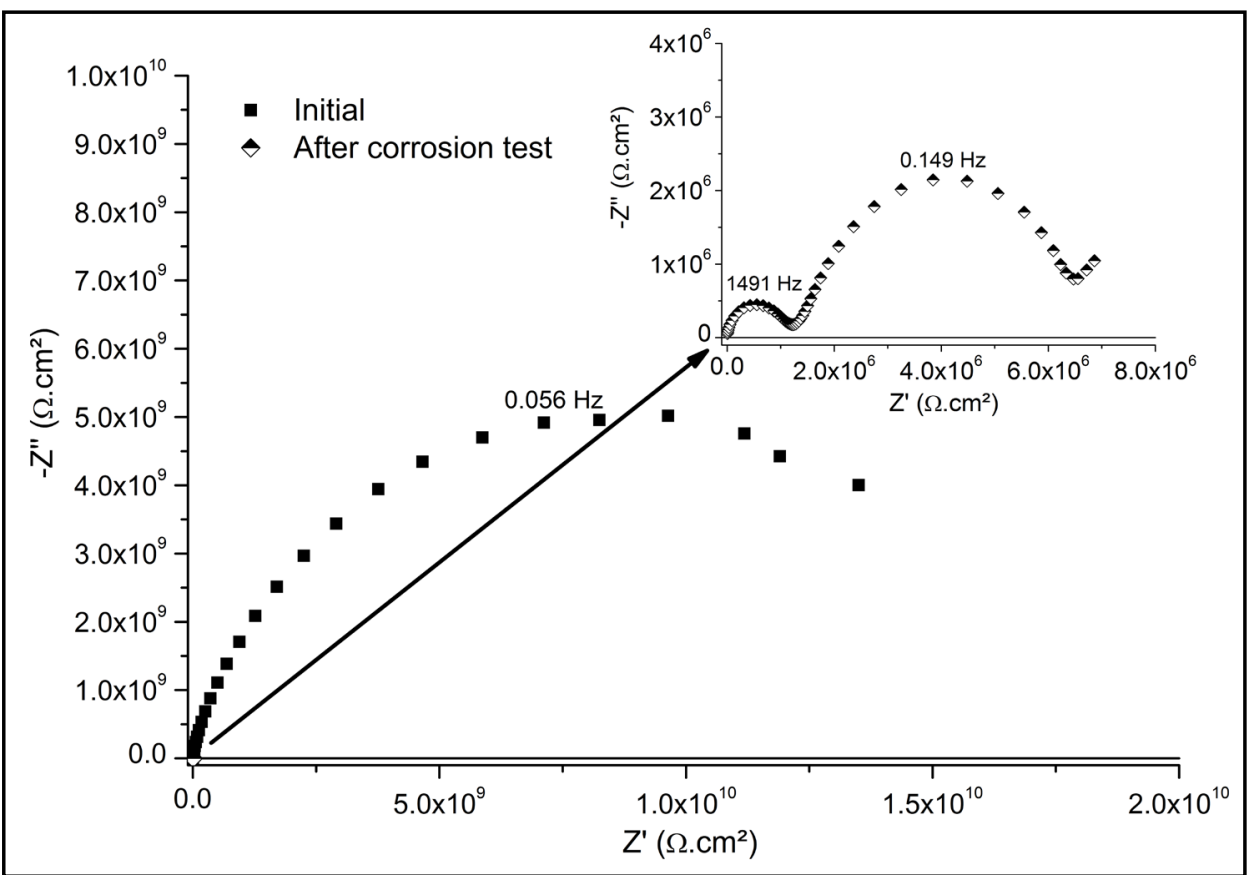

Figure 13. Nyquist plots for sample 5B of painted carbon steel, in $3.5 \% \mathrm{NaCl}$ solution. 


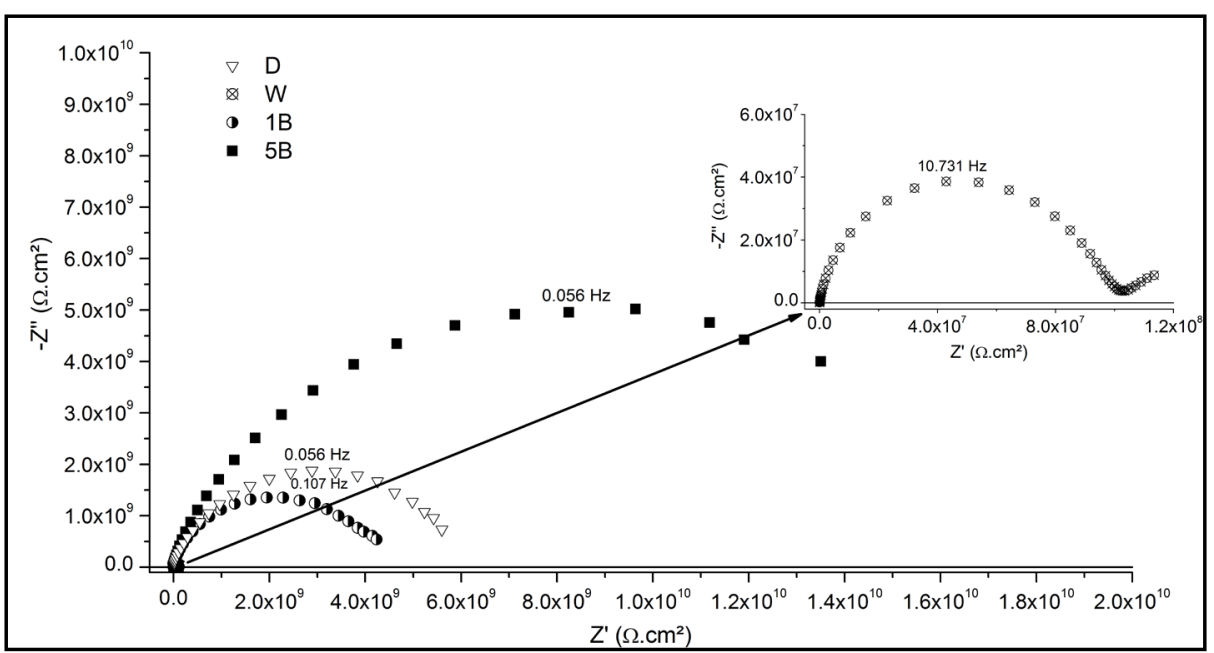

Figure 14. Nyquist plots for painted carbon steel samples, in $3.5 \% \mathrm{NaCl}$ solution. In the subtitle, D refers to the dry blasted painted sample, the other designations to the washed samples, using deonized water (W), $1 \%$ borax solution (1B) and $5 \%$ borax solution (5B).

\section{Conclusions}

In this work, mass loss, electrochemical adhesion and accelerated corrosion tests were carried out to investigate the corrosion inhibition properties of borax solutions and their behavior if used during wet abrasive blasting prior to coating of steel and zinc metallic surfaces.

By mass loss and electrochemical results with unpainted metal samples, it is evident that borax solutions play an anodic inhibition role, mainly at $1 \%$ content. In open operations, such as wet abrasive blasting processes of transmission towers, this corrosion inhibitor content would be very difficult to control.

If left as a residue under the paint system, borax acts more like a soluble salt contaminant than a corrosion inhibitor. In fact, it promotes water permeability through the coating, gets wet and accelerates blistering and corrosion between the metallic substrate and the coating.

The flash rusted surface obtained by deionized water washing prior to coating was not as critical to the performance of the paint system as it was in the case when borax residues were left in the metallic surface. So, paints tolerant to flash rusted surfaces, in which soluble salts are absent, can be applied and may have an anticorrosive performance as good as the same paints applied in a dry blasted surface. Moreover, the use of a soluble-salt type corrosion inhibitor is not recommended during wet abrasive blasting processes.

The effect of other types of corrosion inhibitor, such as organic ones, on the anticorrosive performance of a paint system may be investigated as a suggestion for further study on this subject.

\section{References}

[1] Jones, D.A. (1992) Principles and Prevention of Corrosion. Macmillan Publishing Compa- 
ny, New York.

[2] Fuente, D., Chico, B. and Morcillo, M. (2006) The Effects of Soluble Salts at the Metal/Paint Interface: Advances in Knowledge. Portugaliae Electrochimica Acta, 24, 191-206.

http://dx.doi.org/10.4152/pea.200602191

[3] Amorim, C.C., Café, Y.H.P., Sá, M.M. and Ordine, A.P. (2016) Efeito da Preparação de Superfície de Aço Carbono na Formação de Produtos de Corrosão sob Tinta Epóxi. Proceedings of the 6 th International Corrosion Meeting, INTERCORR 2016, Búzios, 16-20 May 2016, 1-11.

[4] Sá, M.M., Ordine, A.P., Oliveira, W.P. and Amorim, C.C. (2016) Avaliação de Sistemas de Proteção Anticorrosiva para Manutenção de Estruturas Enterradas em Aço Galvanizado. Proceedings of the 6th International Corrosion Meeting, INTERCORR 2016, Búzios, 16-20 May 2016, 1-17.

[5] Momber, A. (2012) Colour-Based Assessment of Atmospheric Corrosion Products, Namely of Flash Rust, on Steel. Materials and Corrosion, 63, 333-342.

http://dx.doi.org/10.1002/maco.201005831

[6] Wienert, L.A. (1978) Resistance to Flash Rusting and Corrosion Undercutting of WaterThinned Paint Films Containing Barium Metaborate. Anti-Corrosion Methods and Materials, 25, 10-14. http://dx.doi.org/10.1108/eb007060

[7] Kalendová, A. (2002) Methods for Testing and Evaluating the Flash Corrosion. Progress in Organic Coatings, 44, 201-209. http://dx.doi.org/10.1016/S0300-9440(02)00014-0

[8] SSPC-VIS 4/NACE VIS 7 (2014) Guide and Reference Photographs for Steel Surfaces Prepared by Waterjetting.

[9] Wilson, L. (2012) The Paint Inspector's Field Guide: For Protective Coating Inspection. TQC-USA Inc., Michigan.

[10] Peters, H. (2004) Surface-Preparation Chemicals for Salt Decontamination or Flash Rust Inhibition. Materials Performance, 28, 28-30.

[11] Rajagopalan, K.S., Venu, K. and Viswanathan, M. (1969) Activation of Passivated Steel in Borax Solution. Corrosion Science, 9, 169-177. http://dx.doi.org/10.1016/S0010-938X(69)80027-2

[12] Desai, M.N., Rana, S.S. and Gandhi, M.H. (1973) Corrosion Inhibitors for Zinc. Anti-Corrosion Methods and Materials, 20, 2-6. http://dx.doi.org/10.1108/eb006939

[13] Shreir, L.L. (1976) Corrosion Control. Newnes-Butterworths, London.

[14] Eletrobras (2016) Eletrobras Standards for Anticorrosive Service Painting. www.eletrobras.com.br/elb/normaseletrobrasdepinturaanticorrosiva

[15] ISO 8407 Standard (2009) Corrosion of Metals and Alloys-Removal of Corrosion Products from Corrosion Test Specimens.

[16] ASTM D 4585 Standard (2013) Standard Practice for Testing Water Resistance of Coatings Using Controlled Condensation.

[17] ISO 4628-2 Standard (2003) Paints and Varnishes-Evaluation of Degradation of Paint Coatings-Designation of Intensity, Quantity and Size of Common Types of Defect, Part2: Designation of Degree of Blistering.

[18] ASTM D 4541 Standard (2009) Standard Test Method for Pull-Off Strength of Coatings Using Portable Adhesion Testers. 
Submit or recommend next manuscript to SCIRP and we will provide best service for you:

Accepting pre-submission inquiries through Email, Facebook, LinkedIn, Twitter, etc. A wide selection of journals (inclusive of 9 subjects, more than 200 journals)

Providing 24-hour high-quality service

User-friendly online submission system

Fair and swift peer-review system

Efficient typesetting and proofreading procedure

Display of the result of downloads and visits, as well as the number of cited articles

Maximum dissemination of your research work

Submit your manuscript at: http://papersubmission.scirp.org/

Or contact msa@scirp.org 